\title{
A New Perspective of Wavelet Based Image Denoising Using Different Wavelet Thresholding
}

\author{
Tapan Kumar Hazra ${ }^{1}$, Arpita Mazumder ${ }^{2}$, Dipsikha Maity ${ }^{3}$ \\ 1, 2, ${ }^{3}$ Institute of Engineering \& Management, Department of Information Technology, \\ Y-12, Salt Lake Electronics Complex, Sector - V, Kolkata - 700 091, West Bengal, India
}

\begin{abstract}
In this paper, the basic principles of digital image processing and image denoising algorithms are summarized. Till now digital image processing has very large scope almost all of the technical domain i.e. image enhancement, image compression, image synthesis, image restoration, image denoising and image analysis. Present paper focuses in the domain of Image denoising. Image denoising is a process of removing noise without affecting and distorting the image and produce a better quality of denoised image. In the present paper, authors observes the effect of various wavelet thresholding methods such as Visushrink, Bayesshrink, Sureshrink and compare all of these with respect to denoised image and introduce a proposed denoising algorithm to determine that it gives better result compare to existing methods.
\end{abstract}

Keywords: wavelet transform, thresholding, image denoising, Visushrink, Sureshrink, Bayesshrink.

\section{Introduction}

In digital era image processing is one of the most fundamental conceptual area. But whenever an image is converted from one form to another, such as digitizing, transmitting or scanning, some form of degradation occurs at the output and the image is noisy. So, Image denoising techniques became very popular that aim to remove the noise, to diminish the effect of surpassing noise and to soften the false outlines that may be present in the digital image. Some incipient techniques, recommended for image denoising process, were based on spatial filter and FFT (fast Fourier transform) filter [1]. But till some cons are found in those filter i.e. it cannot preserve the edges, blurred image, shifts the boundaries, manipulates and localized in terms of frequency. These problems are resolved by wavelet transform which is a time frequency representation of any kind of 2D signal and responds with denoising algorithms with edge preservation. WL (wavelet) transform will discard the low amplitude noise or unwanted components of the 2D signal in the WL (wavelet) [1] .Here we will discuss four threshold based filtering technique for denoising viz. Visushrink (universal thresholding technique), Sureshrink (subband adaptive thresholding technique) and Bayesshrink(spatial adaptive threshholding technique) and proposed filter (weighted average based fusion filtering technique). These thresholding techniques are applied through different kind of noises and different test images for comparing the resulting denoised images and the best wavelet thresholding technique is proposed.

\section{Noise Modelling}

The unwanted components present in an image or $2 \mathrm{D}$ signal is called noise. Basically noise is a disruption that is occurred when the pixel positions and pixel values are randomly fluctuated. Principally we can model a noise in two ways [4].

- $W(x, y)=S(x, y)+N(x, y)$

- $\mathrm{W}(\mathrm{x}, \mathrm{y})=\mathrm{S}(\mathrm{x}, \mathrm{y}) * \mathrm{~N}(\mathrm{x}, \mathrm{y})$
Where,

$\mathrm{S}(\mathrm{x}, \mathrm{y})=$ original clean transmitted image.

$\mathrm{N}(\mathrm{x}, \mathrm{y})=$ noisy signal

$\mathrm{W}(\mathrm{x}, \mathrm{y})=$ corrupted signal or image.

\subsection{Uniform noise}

This noise is not often encountered in real-world imaging systems, but provides a useful comparison with Gaussian noise. The linear average is a comparatively poor estimator for the mean of a uniform distribution. This implies that nonlinear filters should be better at removing uniform noise than Gaussian noise is given as ,Mantosh Biswas and Hari Om(2013) found that An Image Denoising Threshold Estimation Methode`[3].

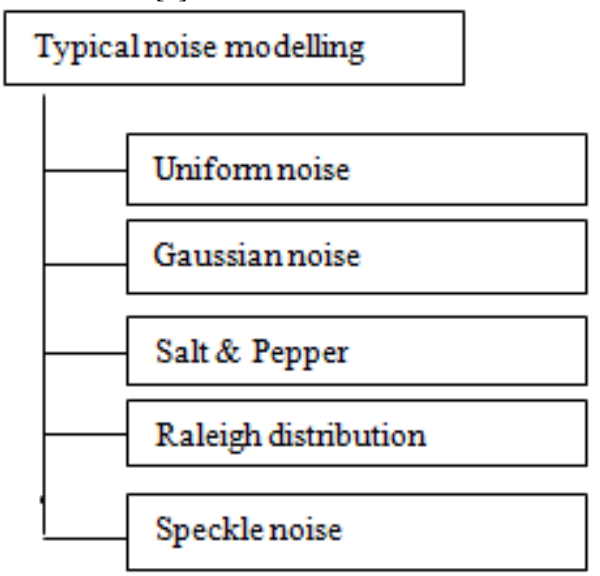

Figure 1: Building block of typical noise modeling

The Uniform PDF (Probability Distribution Function) is given by equation (1)

$$
P(z)=\frac{1}{b-a} \text { for } a \leq f_{i} \leq b \quad=0
$$

Otherwise

Mean $=a+b / 2$ and variance $=\sigma^{2}=(b-a)^{2} / 12$

Where

$\mathrm{z}=$ grey level of the pixel

$\sigma=$ variance 


\section{International Journal of Science and Research (IJSR) \\ ISSN (Online): 2319-7064}

Index Copernicus Value (2013): 6.14 | Impact Factor (2015): 6.391

m=mean

$\mathrm{a}, \mathrm{b}=$ minimum and maximum grey scale values

\subsection{Gaussian distribution (Gaussian noise model)}

The Gaussian distribution is a well-known bell shaped curve. The random noise that enters the system can be modeled as a Gaussian or normal distribution. This is mathematically denoted as, where $\mathrm{N}$ is the Gaussian probability density function and $\mathrm{S}$ is the noiseless image. The dark and light portions of the image are contaminated by Gaussian noise. The Gaussian distribution [8] is given by equation (2).

$$
P(z)=\frac{1}{\sigma \sqrt{2} \cdot .} e^{\wedge} \frac{-(z-m) 2}{2 \sigma 2}
$$

$\mathrm{z}=$ grey level of the pixel

$\sigma=$ variance

$\mathrm{m}=$ mean

$\mathrm{a}, \mathrm{b}=$ minimum and maximum grey scale values

\subsection{Raleigh Distribution}

This type of noise is mostly present in range images. Range images are used in many remote sensing applications where the pixel value indicates the distance between the object and camera system. The PDF (Probability Distribution Function) [6] is given by equation (3).

$$
P(z)=\left\{\begin{array}{c}
\frac{z}{b}(z-a) e^{\frac{-(x-z)^{2}}{b}} \\
0 \text { otherwise }
\end{array}\right.
$$

The mean is given as $+\sqrt{\frac{\pi}{4}}$ and variance is given as $\frac{b(4-\pi)}{4}$ respectively

Where

$\mathrm{z}=$ grey level of the pixel

$\sigma=$ variance

$\mathrm{m}=$ mean

$\mathrm{a}, \mathrm{b}=$ minimum and maximum grey scale values

\subsection{Impulse (Salt \& Pepper noise model)}

This noise is known by various names such as shot noise, Salt and Pepper noise and Binary noise. It is caused by a sudden disturbance in the image signal. The noise is occurred due to sensor and storage problems by which pixels are allotted in incorrect maximum values.

The PDF is given as

$$
\begin{gathered}
\mathrm{H}(\mathrm{z})=\text { Pa for } z=a \\
=\text { Pb for } z=b \\
0 \text { elsewhere }
\end{gathered}
$$

$\mathrm{z}=$ gray level of the pixel.

$\mathrm{a}, \mathrm{b}=$ minimum and maximum grey scale values of the image respectively.

\subsection{Speckle Noise Model}

In medical image processing, exceptionally ultrasound image processing usage of Speckle noise is immeasurable. Basically Speckle noise is considered as a multiplicative noise. Moreover its average amplitude is always increases with the corresponding signal intensity. In the illuminated area of the image it arises as bright specks. As it is under multiplicative noisy model classification, so it can be mathematically generalized as a pixel value multiplied by random value. Usually Speckle noise [5] is given by equation (5).

$$
\mathrm{I}=\mathrm{S}+(\mathrm{S} * \mathrm{~N})
$$

Where,

$\mathrm{N}$ = random noise having a zero mean Gaussian probability distributive function

$\mathrm{S}=$ random signal

\section{Benefits of wavelet transform over Fourier transform}

- Fourier Transform works well with periodic signals, but it is not very effective with signals having sharp peaks and valleys. In addition, one of the major disadvantage $s$ of Fourier transform is the loss of timing information of the signals. On the other hand, wavelet transform gives frequency as well as time information [6].

- Wavelet transforms gives good frequency resolution for low frequency components which are basically the average intensity values of the image and give high temporal resolution for high frequency components which are basically the edges of the digital image [10].

- Basically Wavelet is a small wave used to approximate the given signal effectively.

- Wavelet transforms are faster and robust in nature and provide better compression as images are sparse after wavelet transform and wavelets are more adaptive compared to the Fourier transform [7].

For this reason wavelets are convenient in wide area of applications such as image compression, image denoising, seismic data processing, and speech processing.

\section{Wavelet based thresholding technique}

In this context we discuss about three soft thresholding methods are as follows:

- Visu Shrink

- Sure Shrink

- Bayes Shrink

\subsection{Visushrink method}

Dohono introduced Visushrink technique. Generally it works with the additive Gaussian noise. But there are some flaws in Visushrink method, such as it cannot properly minimize the MSE value and does not work well with the speckle noise or better we can say that multiplicative noise. Here threshold Tc which is given by [7] equation (6) is given by and variance $\sigma$ is calculated by equation (7)

$$
\begin{gathered}
T c=\sigma \sqrt{2 \log m} \\
\sigma^{2}=\left[\frac{\operatorname{median}(|x i j|)}{0.675}\right]^{2}, X_{i j e H H 1}
\end{gathered}
$$

Where $\sigma=$ variance

$\mathrm{m}=$ mean

HH1=detail subband

The steps are shown in figure 3.

\section{Volume 5 Issue 8, August 2016}




\section{International Journal of Science and Research (IJSR) \\ ISSN (Online): 2319-7064}

Index Copernicus Value (2013): 6.14 $\mid$ Impact Factor (2015): 6.391

\subsection{Sureshrink Method}

The Sureshrink was proposed by Donoho and Johnstone to overcome the problem of Visushrink i.e. getting overly smoothed image with high probability .D.L.Donoho used the combination of both the universal and Sureshrink thresholds and suggested to choose the optimal threshold value $\mathrm{T}$ by minimizing Sure [9]. The significance of this is that it is possible to transform the original data into its WC (wavelet coefficients), and then attempt to minimize risk in the wavelet domain; doing so will automatically minimize risk in the original domain. In practical situation the risk $R(f \wedge, f)$ must be estimated from the data. This method employs an unbiased estimate of risk that is due to Stien called Stien Unbiased Risk Estimator (SURE).

The Sureshrink threshold, $T_{\text {sure }}$, is defined as equation(8)

$$
\mathrm{T}_{\text {sure }}=\min \left(\mathrm{t}_{\mathrm{j}}, \sigma \sqrt{2} \mathrm{logm}\right)
$$

Where $\sigma=$ variance

$\mathrm{m}=$ mean

$t_{j}=$ jth decomsition level in wavelet

The steps are shown in figure 4 .

\subsection{Bayesshrink Method}

In this context we discuss about another wavelet thresholding technique i.e. Bayes Shrink method. It is a soft thresholding algorithm for removing the Gaussian noise. On the basis of image denoising in this framework Bayesian estimator expressed as the most fruitful phenomena of wavelet based thresholding. Basically for each sub bands Bayes shrink estimator evaluates different threshold value and place it in its proper position [11]. Here subbands refer to frequency bands that are different from each other in level and direction. For a specific level it directly computes $\mathbf{K}$ not having the benefits of soft or hard thresholding. Previously we know GDD is assumed for the wavelets coefficients in each detail sub-band and in Bayesian estimator survey, the thresholding procedure is determined [7]. So, the key purpose of Bayesian estimator is to compute such a threshold value that can minimize the Bayesian risk and MSE value assuming Generalized Gaussian Distribution (GGD) prior. The GDD is given by

$$
\begin{gathered}
G G \sigma \chi, \beta(x)=\left[C(\sigma x, \beta) \exp \left[-\left\{\alpha(\sigma x, \beta) \|_{x}\right]^{\beta}\right]\right. \\
-\infty<x<\infty, \sigma x>0, \beta>0 \\
\alpha(\sigma x, \beta)=\sigma^{-1} x\left[\frac{\mathrm{r}\left(\frac{s}{\beta}\right)}{\mathrm{r}\left(\frac{3}{\beta}\right)}\right]^{1 / 2} \\
C\left(\sigma_{x}, \beta\right)=\frac{\beta \cdot \alpha\left(\sigma_{x}, \beta\right)}{2 \mathrm{r}\left(\frac{1}{\beta}\right)} \\
\mathrm{r}(t)=\int_{0}^{\infty} e^{-u} U^{t-1} \text { duisthegammafunction }
\end{gathered}
$$

To compute the data driven estimate, the GDD parameters and needs to be evaluated

$$
\sigma^{2} Y=\sigma^{2} x+\sigma^{2}
$$

Here $\mathrm{Y}$ is modeled as 0 mean and

$$
\sigma^{2} Y=\frac{1}{n^{2} i, \sum_{j=1}^{n} Y i j^{2}}
$$

Here $n \times n=$ size of sub domain. Also, is defined as

$$
\sigma^{2} x=\max \left(\sigma^{2} Y, \sigma^{2}, 0\right)
$$

Now Bayesian threshold is calculated and defined below

$$
T_{\bar{B}}=\frac{\sigma^{2} x}{\sigma^{2}}
$$

The steps are shown in figure 5 .

\section{Proposed algorithm}

Step 1: An input image is taken.

Step 2: Add different types of noise (i.e. Gaussian noise, Salt \& Pepper noise, Speckle noise) with respect to different noise variance.

Step 3: Calculate the weighted average of the threshold value of Visushrink, Bayesshrink and Sureshrink by using the following formula

$$
\begin{aligned}
& \frac{(.2 \times x 1)+(.6 \times x 2)+(.2 \times x 3)}{10} \\
& \& \\
& (.25 \times x 1)+(.5 \times x 2)+(.25 \times x 3)
\end{aligned}
$$$$
10 \text { where } x 1, x 2, x 3
$$

are threshold value of visu bayes and sure shrink

Calculated value is (1.71)

Step 4: Decompose the noisy image at level 1. It gives four coefficients Approximation, Vertical, Horizontal, Diagonal.

Step 5: Apply universal threshold i.e. Visushrink on the 3 coefficients using weighted average as the threshold value \& it is calculated based on diagonal coefficient only.

Step 6: approximate coefficient is decomposed up to given level and sure threshold is calculated using equations given above and apply to all coefficients one by one.

Step 7: Apply inverse discrete wavelet transform.

Step 8: First image is reconstructed from the coefficient which is threshold by Sureshrink. Second final recovered image is constructed from the coefficient which is threshold by Visushrink and resultant coefficient of first step.

\section{Experimental Results}

To see the qualitatively as well as quantitatively performance of the proposed algorithm, the experimental study has been performed on several RGB test images. In our experiment six test images are used which is shown in figure 6 . For each test images, three noisy versions were created by adding noise. The noisy images are denoised with all methods: Visushrink with steps specified in figure 3, Sureshrink with steps specified in figure 4. Bayesshrink with steps specified in figure 5 and Proposed Method. The results are compared qualitatively (visually) as well as quantitatively using quality measures PSNR, MSE, and RMSE. Figure 6 gives the original test images \& the following six tables (1-6) shown that the proposed fusion filter gives the best result and after that all the experimental result's screenshots are given below. 
International Journal of Science and Research (IJSR)

ISSN (Online): 2319-7064

Index Copernicus Value (2013): 6.14 | Impact Factor (2015): 6.391

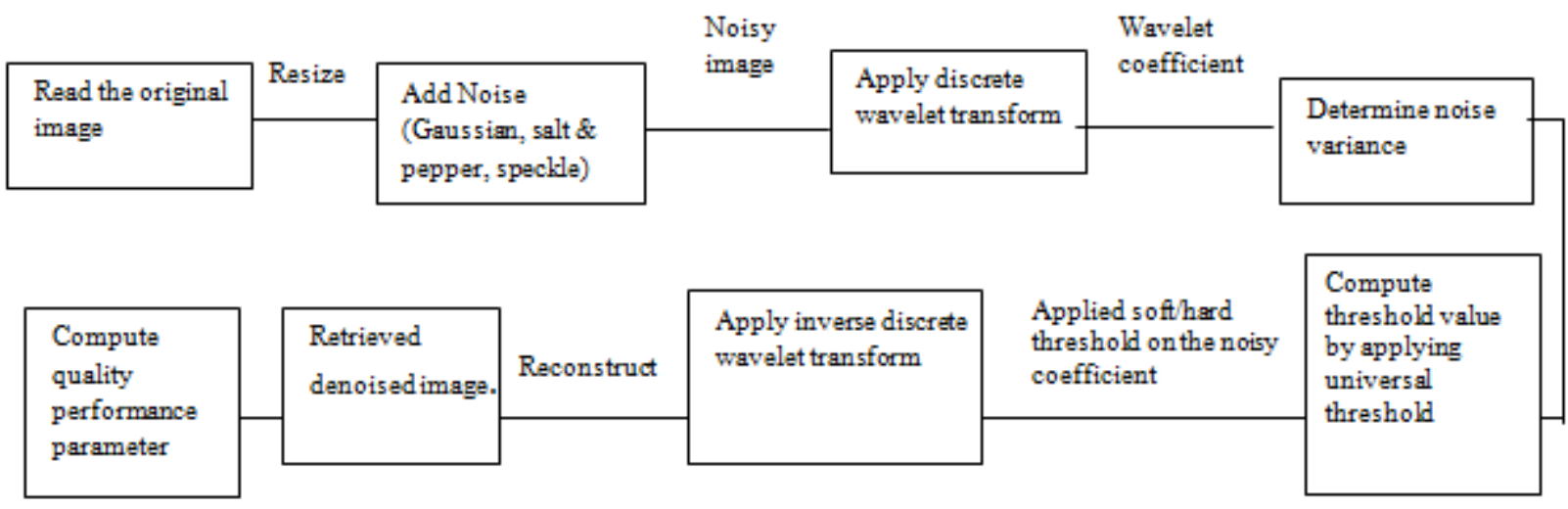

Figure 3: Building block of Visushrink

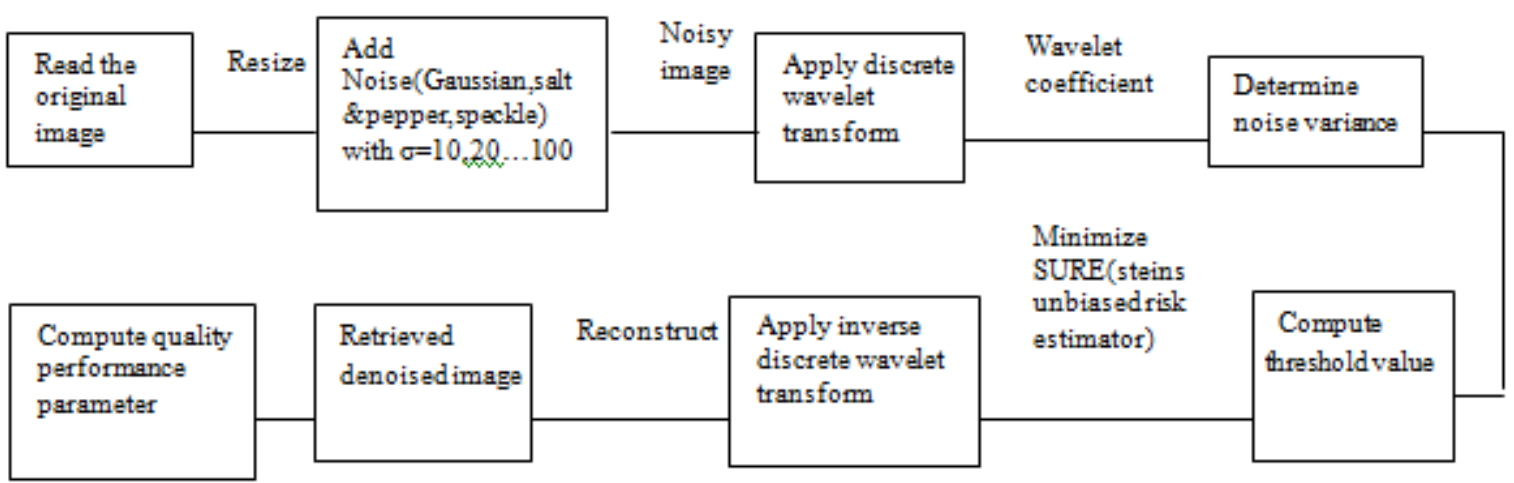

Figure 4: Building block of Sureshrink

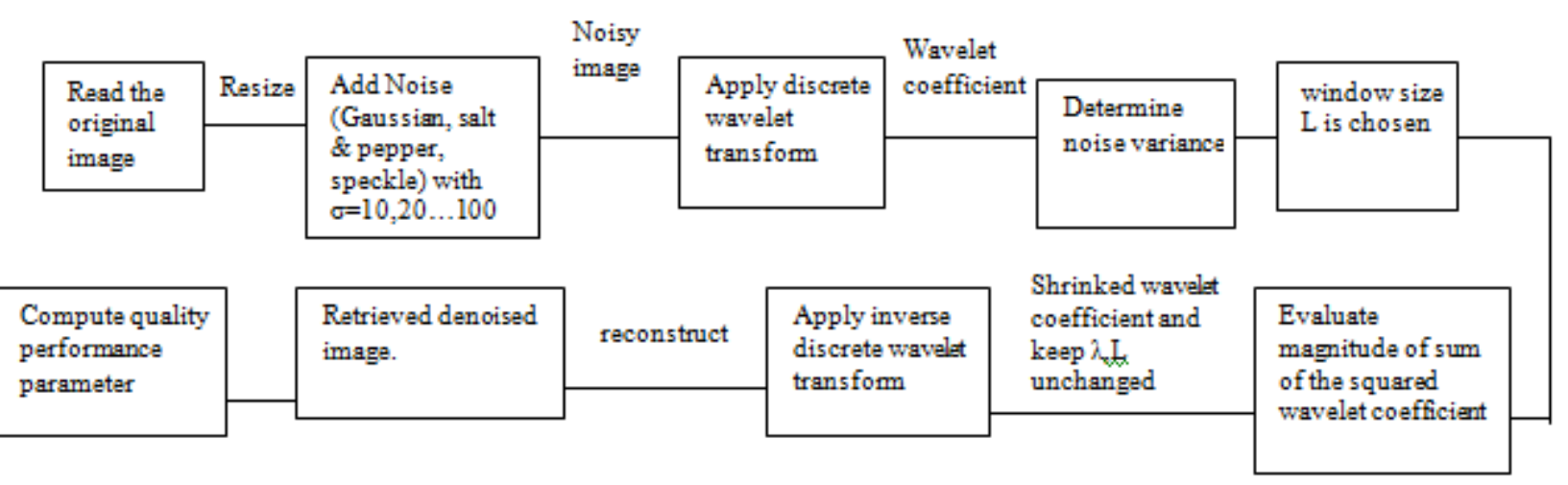

Figure 5: Building block of Bayesshrink
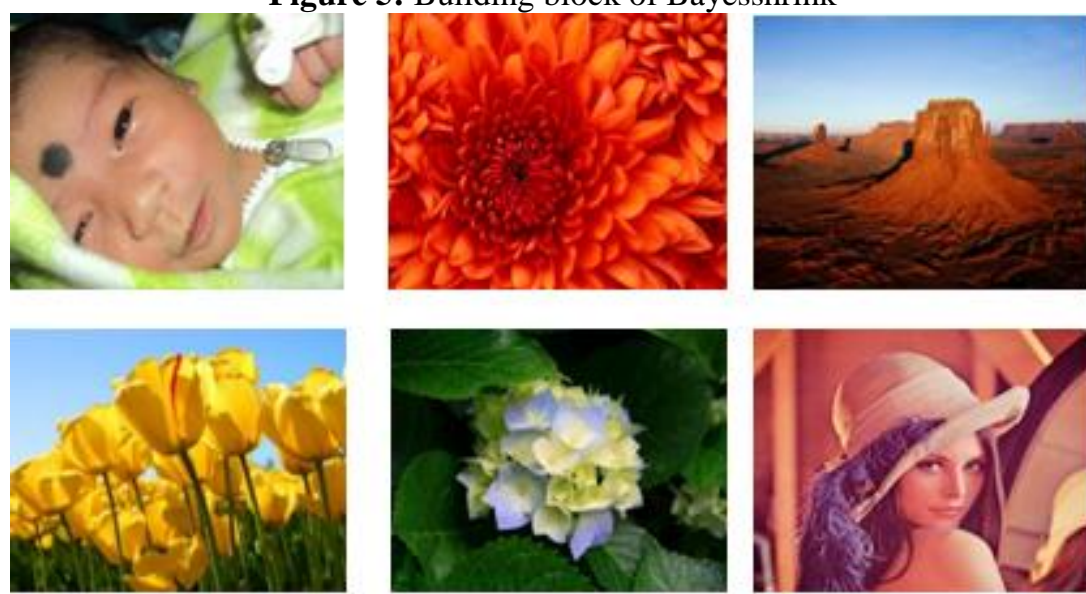

Figure 6: Original test images

\section{Volume 5 Issue 8, August 2016}

www.ijsr.net

Licensed Under Creative Commons Attribution CC BY 


\section{International Journal of Science and Research (IJSR) \\ ISSN (Online): 2319-7064 \\ Index Copernicus Value (2013): 6.14 | Impact Factor (2015): 6.391}

Table 1: Results of Baby.jpg

\begin{tabular}{|c|c|c|c|c|}
\hline Shrinkage & Noise & PSNR & MSE & RMSE \\
\hline Visushrink & \multirow{4}{*}{$\begin{array}{l}\text { Salt \& } \\
\text { Pepper }\end{array}$} & 29.82 & 67.74 & 8.23 \\
\hline Sureshrink & & 32.23 & 38.87 & 6.23 \\
\hline Bayesshrink & & 32.02 & 40.80 & 6.39 \\
\hline Proposed fusion filter & & 34.87 & 21.18 & 4.60 \\
\hline Visushrink & \multirow[t]{4}{*}{ Gaussian } & 24.71 & 219.96 & 14.83 \\
\hline Sureshrink & & 24.06 & 255.19 & 15.97 \\
\hline Bayesshrink & & 30.56 & 57.22 & 7.56 \\
\hline Proposed fusion filter & & 31.16 & 49.80 & 7.06 \\
\hline Visushrink & \multirow{4}{*}{ Speckle } & 28.20 & 98.52 & 9.93 \\
\hline Sureshrink & & 27.82 & 107.48 & 10.37 \\
\hline Bayesshrink & & 30.78 & 54.34 & 7.37 \\
\hline Proposed fusion filter & & 32.68 & 35.08 & 5.92 \\
\hline
\end{tabular}

Table 2: Results of Desert.jpg

\begin{tabular}{|c|c|c|c|c|}
\hline Shrinkage & Noise & PSNR & MSE & RMSE \\
\hline Visushrink & \multirow{4}{*}{$\begin{array}{l}\text { Salt \& } \\
\text { Pepper }\end{array}$} & 28.74 & 86.92 & 9.32 \\
\hline Sureshrink & & 29.89 & 66.62 & 8.16 \\
\hline Bayesshrink & & 29.78 & 68.34 & 8.00 \\
\hline Proposed fusion filter & & 30.22 & 61.87 & 7.87 \\
\hline Visushrink & \multirow[t]{4}{*}{ Gaussian } & 24.46 & 233.07 & 15.27 \\
\hline Sureshrink & & 24.60 & 255.50 & 15.02 \\
\hline Bayesshrink & & 27.12 & 126.25 & 11.24 \\
\hline Proposed fusion filter & & 27.44 & 117.27 & 10.83 \\
\hline Visushrink & \multirow[t]{4}{*}{ Speckle } & 28.61 & 89.58 & 9.46 \\
\hline Sureshrink & & 28.63 & 89.17 & 9.44 \\
\hline Bayesshrink & & $28 . .85$ & 84.65 & 9.20 \\
\hline Proposed fusion filter & & 29.64 & 70.57 & 8.40 \\
\hline
\end{tabular}

Table 3: Results of Chrysanthemum.jpg

\begin{tabular}{|c|c|c|c|c|}
\hline Shrinkage & Noise & PSNR & MSE & RMSE \\
\hline Visushrink & \multirow{4}{*}{$\begin{array}{l}\text { Salt \& } \\
\text { Pepper }\end{array}$} & 28.23 & 97.66 & 9.88 \\
\hline Sureshrink & & 30.64 & 56.13 & 7.49 \\
\hline Bayesshrink & & 30.46 & 58.50 & 7.65 \\
\hline Proposed fusion filter & & 32.17 & 39.49 & 6.28 \\
\hline Visushrink & \multirow[t]{4}{*}{ Gaussian } & 24.45 & 233.46 & 15.28 \\
\hline Sureshrink & & 25.33 & 190.40 & 11.80 \\
\hline Bayesshrink & & 26.34 & 150.87 & 12.28 \\
\hline Proposed fusion filter & & 26.87 & 133.71 & 11.56 \\
\hline Visushrink & \multirow[t]{4}{*}{ Speckle } & 29.83 & 67.79 & 8.23 \\
\hline Sureshrink & & 29.92 & 66.26 & 8.14 \\
\hline Bayesshrink & & 29.84 & 67.53 & 8.22 \\
\hline Proposed fusion filter & & 30.60 & 56.60 & 7.52 \\
\hline
\end{tabular}

Table 4: Results of Tulips.jpg

\begin{tabular}{|c|c|c|c|c|}
\hline Shrinkage & Noise & PSNR & MSE & RMSE \\
\hline Visushrink & \multirow[t]{4}{*}{ Salt \& Pepper } & 26.81 & 89.49 & 9.46 \\
\hline Sureshrink & & 31.16 & 49.74 & 7.05 \\
\hline Bayesshrink & & 31.02 & 51.39 & 7.17 \\
\hline Proposed fusion filter & & 32.00 & 42.74 & 6.54 \\
\hline Visushrink & \multirow[t]{4}{*}{ Gaussian } & 24.52 & 229.81 & 15.16 \\
\hline Sureshrink & & 24.60 & 225.44 & 15.01 \\
\hline Bayesshrink & & 26.56 & 143.45 & 11.98 \\
\hline Proposed fusion filter & & 27.45 & 117.00 & 10.82 \\
\hline Visushrink & \multirow[t]{4}{*}{ Speckle } & 28.23 & 97.84 & 9.89 \\
\hline Sureshrink & & 28.35 & 95.17 & 9.76 \\
\hline Bayesshrink & & 28.24 & 97.48 & 9.87 \\
\hline Proposed fusion filter & & 29.54 & 72.29 & 8.50 \\
\hline
\end{tabular}

Table 5: Results of Hydrangeas.jpg

\begin{tabular}{|c|c|c|c|c|}
\hline Shrinkage & Noise & PSNR & MSE & RMSE \\
\hline Visushrink & \multirow{4}{*}{$\begin{array}{l}\text { Salt \& } \\
\text { Pepper }\end{array}$} & 28.61 & 89.63 & 9.47 \\
\hline Sureshrink & & 31.09 & 50.66 & 9.11 \\
\hline Bayesshrink & & 30.94 & 52.36 & 7.24 \\
\hline Proposed fusion filter & & 32.28 & 38.48 & 6.20 \\
\hline Visushrink & \multirow[t]{4}{*}{ Gaussian } & 24.65 & 223.11 & 14.94 \\
\hline Sureshrink & & 25.28 & 192.80 & 13.89 \\
\hline Bayesshrink & & 27.79 & 108.05 & 10.39 \\
\hline Proposed fusion filt & & 27.80 & 107.68 & 10.30 \\
\hline Visushrink & \multirow[t]{4}{*}{ Speckle } & 32.31 & 38.16 & 6.18 \\
\hline Sureshrink & & 32.40 & 37.40 & 6.12 \\
\hline Bayesshrink & & 32.29 & 38.38 & 6.20 \\
\hline Proposed fusion filter & & 33.00 & 36.71 & 6.00 \\
\hline
\end{tabular}

Table 6: Results of Lena.jpg

\begin{tabular}{|c|c|c|c|c|}
\hline Shrinkage & Noise & PSNR & MSE & RMSE \\
\hline Visushrink & \multirow{4}{*}{\begin{tabular}{|l|} 
Salt \& \\
Pepper
\end{tabular}} & 29.97 & 65.49 & 8.09 \\
\hline Sureshrink & & 30.60 & 56.64 & 7.53 \\
\hline Bayesshrink & & 30.47 & 58.35 & 7.64 \\
\hline Proposed fusion filter & & 31.00 & 53.64 & 7.29 \\
\hline Visushrink & \multirow[t]{4}{*}{ Gaussian } & 29.05 & 80.92 & 9.00 \\
\hline Sureshrink & & 27.57 & 113.82 & 10.67 \\
\hline Bayesshrink & & 29.50 & 72.99 & 8.54 \\
\hline Proposed fusion filter & & 30.40 & 59.37 & 7.71 \\
\hline Visushrink & \multirow[t]{4}{*}{ Speckle } & 24.59 & 226.12 & 15.04 \\
\hline Sureshrink & & 23.38 & 298.84 & 17.29 \\
\hline Bayesshrink & & 29.25 & 77.34 & 8.79 \\
\hline Proposed fusion fi & & 29.33 & 75.89 & 8.70 \\
\hline
\end{tabular}

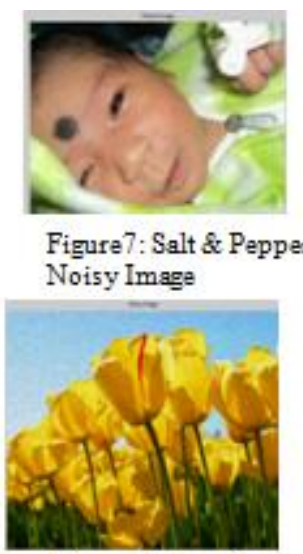

Figure 12: Speckle Noisy Image

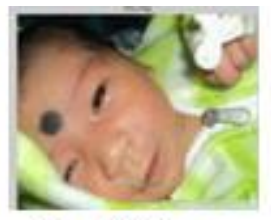

Figure8: Visu Filtered Image

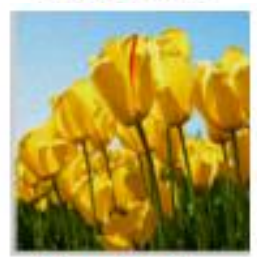

Figure13: Visu filtered Image

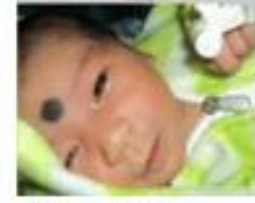

Figure9: Sure filtered Image

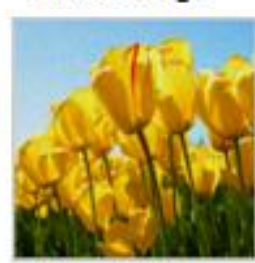

Figure14: Sure filtered Image

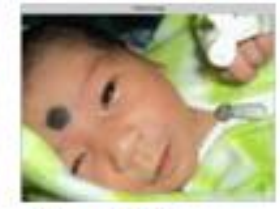

Figure10: Bayes filtered Image

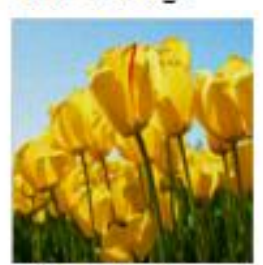

Figure15: Bayes filtered Image

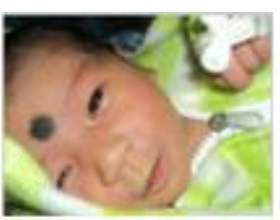

Figurel1:

Proposed filtered

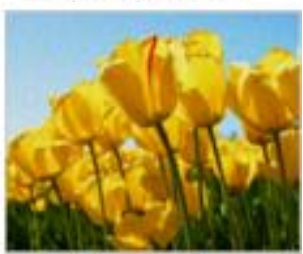

Figure 16: Proposed filtered Image

\section{Volume 5 Issue 8, August 2016 www.ijsr.net}




\section{International Journal of Science and Research (IJSR) \\ ISSN (Online): 2319-7064}

Index Copernicus Value (2013): 6.14 | Impact Factor (2015): 6.391

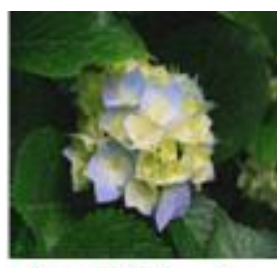

Figure17:Gaussian Noisy Image

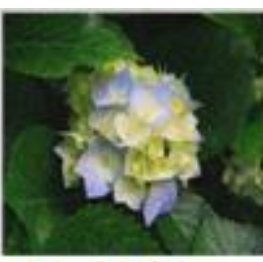

Figure18: Visu filtered Image

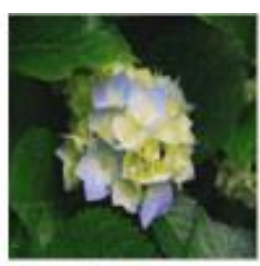

Figure19: Bayes filtered Image

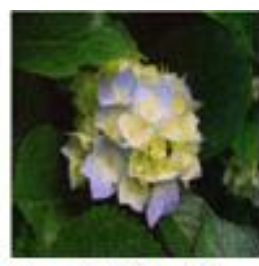

Figure20: Sure filtered Image

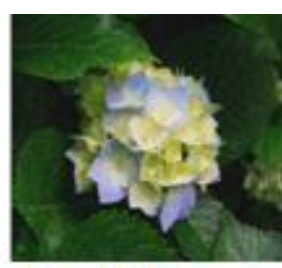

Figure21: Proposed filtered Image

\section{Conclusion}

In the present paper we have performed a comparative analysis of various image denoising techniques using wavelet transforms. Here we have analysed different denoising methods after making the images noisy by adding Gaussian noise, Speckle noise, Salt\&pepper noise. Then by using different wavelet thresholding techniques like Bayesshrink, Sureshrink, Visushrink and proposed fusion filter we have removed the noise and determined that proposed wavelet thresholding filter gives the better result for image denoising.

\section{References}

[1] Nezamoddin Nezamoddini-Kachouie, Paul Fieguth, BayesShrink,Ridgelets for Image Denoising.

A.Campilho,M.Kamele(Eds.):ICIAR2004,LNC3211,PP. 163-170,2004C Springer-Verlag Berlin Heidelberg 2004,BayesShrinkRidgelets for Image Denoising,2004.

[2] S.Sudha, G.R.Suresh, R.Sukanesh, Wavelet International Conference on Computational Intelligence and Multimedia Applications, January-2008.

[3] DivyaSharma,Electrical and Instrumentation Engineering Department,Thapar University, A comparative Analysis of Thresolding techniques Used in Image Denoising Through Wavelets,June-2008.

[4] Abhinandan Kalita, Md.SajjadHossain, Kandarpa Kumar Sarma, A New Approach to Image Denoising based on WienerLMMSEScheme

[5] Harleen Kaur Khehra , Chirag Sharma , Parul Chauhan, Performance enhancement of Wavelet Techniques International journal of Emerging Technology and Advanced Engineering,ISSN 2250-2459,ISO 9001-2008 Certified Journal,May-2013.

[6] RaisRabani Bin Abd.Rahman, "Analysis Of NonUniform Surface Current Distribution On Thick And Thin Wire Antenna" pp-7-13 June 2013.

[7] Tang Huila Zengli, Chen Lin, Chen Zaiyu, WaveletImage Denoising Based onThe New Threshold Function ,Proceedings of the 2nd International Conference on Computer Science and Electronics Engineering (ICCSEE 2013),2013.

[8] Anutam and Rajni, COMPARATIVE ANALYSIS OF FILTERS AND WAVELET BASED THRESHOLDING METHODS FOR IMAGE DENOISING, DhinaharanNagamalai et al. (Eds) : ACITY, WiMoN, CSIA, AIAA, DPPR, NECO, InWeS 2014 pp. 137-148, 2014. (C) CS \& IT-CSCP 2014,2014.

[9] Aarti, GauravPushkarna,Comparative Study of Image Denoising Algorithms in Digital Image Processing,An International journal of Advanced Computer Technology, ISSN:2320-0790,May-2014.
[10] Arun Dixit, Poonam Sharma, A Comparative Study of Wavelet Thresholding for Image Denoising, I.J. Image, Graphics and Signal Processing, November-2014.

[11] AsemKhmag,AbdRahmanRamli,ShaifulJahariHashim, Syed Abdul Rahman Al-Haddad,Review of Image Denoising Algorithms Based on the Wavelet Transformation ,International Journal of Advanced Trends in Computer Science and Engineering (IJATCSE),ISSN 2278 - 3091,October-2014-2015.

\section{Author Profile}

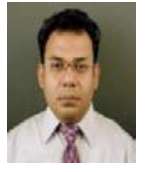

Tapan Kumar Hazra completed his M.E degree from Jadavpur University, Kolkata, West Bengal, India. Since from 2003, he is working as Assistant Professor of Department of Information Technology at Institute of Engineering \& Management, Salt Lake, Kolkata, West Bengal, India. His research interest include Design and Analysis of Algorithms, Image Processing, Natural Language Processing, Sentiment Analysis, Machine learning, Cryptography.

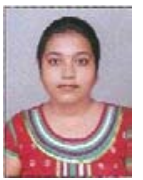

Arpita Mazumder is pursuing M.Tech in Information Technology from Institute of Engineering and Management, Salt Lake, Kolkata, West Bengal, India. His research interests include Image Processing.

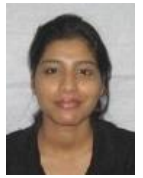

Dipsikha Maity is pursuing M.Tech in Information Technology from Institute of Engineering and Management, Salt Lake, Kolkata, West Bengal, India. His research interests include Image Processing. 